\title{
Effects of PWIM in the ESL Classroom: Vocabulary Knowledge Development Among Primary Malaysian Learners
}

\author{
BEE CHOO LEE \\ School of Languages, Literacies and Translation, \\ Universiti Sains Malaysia \\ AMBIGAPATHY PANDIAN \\ Faculty of Language and Communication, \\ Universiti Malaysia Sarawak \\ SOUBA RETHINASAMY \\ Faculty of Language and Communication, \\ Universiti Malaysia Sarawak \\ DEBBITA AI LIN TAN (Corresponding Author) \\ School of Languages, Literacies and Translation, \\ Universiti Sains Malaysia \\ debbita_tan@usm.my
}

\begin{abstract}
The present quasi-experimental study examined the impact of pictures, via a modified version of Emily Calhoun's (1999) Picture Word Inductive Model (PWIM), on the English vocabulary acquisition of Malaysian Year 1 pupils in a rural national primary school. Meara and Buxton's (1987) Yes-No Recognition Test (YNRT) was adapted and further tested for reliability to measure the recall and retention of subjects'vocabulary size. A total of 60 subjects participated in the research, comprising two intact classes; one class formed the Experimental group and the other formed the Control group. The former underwent the intervention while the latter received typical classroom instruction. Results gleaned from independent samples t-tests revealed superior vocabulary scores at the posttest and delayed posttest levels by the Experimental group, denoting greater vocabulary knowledge recall and retention that reflects the effectiveness of the intervention in enhancing vocabulary acquisition among young Malaysian learners. This study and its findings are of significance to English language teachers, curriculum designers, policy makers, and scholars engaged in ESL/EFL research. It is also noteworthy that there exists a paucity with regards to in-depth research on the use of images for language learning among young learners, particularly within the Malaysian context.
\end{abstract}

Keywords: pictures; PWIM; vocabulary recall and retention; young learners; Malaysia

\section{INTRODUCTION}

Concern with the state of Malaysian younger workforce's English language proficiency propelled the present research. It is an unpropitious omen for the Malaysian society when its graduates have been touted time and again as being not of employable material due to their inferior proficiency in English (Hire in Asia, 2018). The previous government has certainly taken note and concern can be discerned in the various education reforms implemented over the decades with the Subject Grade Point Average as among the most recent attempt in helping students in the country to excel in the language. Other reforms include the Malaysia English Language Roadmap (2015-2025), Malaysia Education Blueprint (2013-2025) and the Primary School Standards-Based Curriculum for English language education (SBELC), introduced in 2011. Likewise, as mentioned by Campbell (2018), post Malaysia $14^{\text {th }}$ General Election, the freshly minted government too needs to commit to a reform specifically targeting at raising English language proficiencies. In short, there exists a need for an effectual language learning approach to elevate the level of English among Malaysians. 